\title{
Performance-based design of stainless steel profiled barrier blast walls
}

\author{
Mohammad H. Hedayati ${ }^{1}$, Srinivas Sriramula ${ }^{2}$ and Richard D. Neilson ${ }^{2}$ \\ ${ }^{1} \mathrm{PhD}$, School of Engineering, University of Aberdeen, UK; and Technical Adviser for ACA \\ ACE Construction Australia Pty Ltd, Australia; e-mail: m.hedayati@acerig.com \\ ${ }^{2}$ School of Engineering, University of Aberdeen, UK; e-mails: $\underline{\text { s.sriramula@abdn.ac.uk; }}$ \\ r.d.neilson@abdn.ac.uk.
}

\begin{abstract}
:
Structural collapse and failures in recent events have uncovered the problem of current design procedures and confirmed the need for new methods and approaches for performance evaluation and design. The main issue is the appropriate consideration and treatment of the various uncertainties in the explosion loadings and the complex blast wall behaviour, considering dynamic and nonlinearity effects in the evaluation and assessment process. To capture these uncertainties or associated effects in the design of profiled barrier blast walls, a new methodology needs to be introduced and developed to perform probabilistic reliability assessment. However, to consider the reliability approach in the design of blast walls appropriately, a performance-based assessment method is required. Therefore, this study presents a framework for performance-based assessment of stainless steel profiled barrier blast walls. Initially, by using the enhanced APDL finite element modelling programming package, a blast wall with consideration of upper and lower connections is developed. Various uncertainties in explosion loadings, material and section properties are considered in the probabilistic assessments. For the performance-based design, performance levels of the blast wall structures are studied at serviceability, damage control and collapse prevention levels. The design criteria and the maximum allowable response values are initially specified
\end{abstract}


to be investigated and discussed and in later stages optimal response target values are proposed for performance-based assessment under various probabilistic explosion loadings (i.e. hazards).

Keywords: Stainless steel blast walls; stainless steel profiled barriers; Performance-based design; Probabilistic assessment; Ansys; Latin Hypercube Sampling.

\section{Abbreviations}

ABS: American Bureau of Shipping

APDL: ANSYS Parametric Design Language

CDF: Cumulative Density Function

DLF: Dynamic Load Factor

FABIG: Fire and Blast Information Group

FEA: Finite Element Analysis

ISO: International Organisation for standardisation

LHS: Latin Hypercube Sampling

MCS: Monte Carlo Simulation

MDOF: Multi Degree of Freedom

NLFEA: Nonlinear Finite Element Analysis

SDOF: Single Degree of Freedom

TN: Technical Note

\section{Nomenclature}

CL1, CL2, CL3, CL4, CL5, CL6, CL7, CL8: Length parameters for the lower and upper connections

CT1, CT2, CT3, CT4, CT5 , CT6, CT7, CT8 : Thickness parameters for the lower and upper connections

EPEL: Maximum elastic equivalent von Mises strain 
EPPL: Maximum Plastic equivalent von Mises strain

EPTO: Maximum total equivalent von Mises strain

L1, L2, L3, S, L and H: the section geometry of blast wall

$P_{0}:$ peak dynamic pressure

t: time

$t_{d}:$ duration of applied load

Tw: thickness of blast wall

$\Theta$ : section angle 


\section{Background}

Stainless steel profiled walls have increasingly been used in the offshore industry because of their excellent energy absorption and temperature dependent properties (Brewerton and FABIG TN5. 1999; Louca and Boh 2004). These structures have lower cost/strength ratio and their installation is fast, compared to other possible ways of protection against explosions (Haifu and Xueguang 2009).

Considering the deterministic response of profiled barrier structures, two approaches are usually recommended for the design: the traditional Single Degree of Freedom (SDOF) approach or the more sophisticated Multi Degree of Freedom (MDOF) approach. The simplified SDOF approach is widely used in the offshore industry for predicting the dynamic structural response by implementing the Biggs method (Biggs 1964). This is a simple approach which idealizes the actual structure as a spring/mass model and is thus very useful in routine design procedures to obtain accurate results for relatively simple structures with limited ductility (Louca and Boh 2004). The SDOF approach is a useful technique for conceptual or basic design of the profiled barrier structures under explosion loadings, whereas, the MDOF method, which is typically based on a Finite Element Analysis (FEA) approach, provides a detailed analysis of the blast wall and is more accurate when compared to the SDOF approach, but is computationally very intensive and, as a result, more expensive. However, with recent developments in computing technology, performing FEA is easier and faster than it was in the past. There have also been some preliminary studies to verify SDOF results against MDOF results (Liang et al. 2007). Nonlinear FEA (NLFEA) can be used to overcome the limitations of normally implemented analytical methods which have mostly been developed to study elastic response or some specific plastic response and do not allow 
for large deformations and unstable responses. In addition, the use of NLFEA can prepare the way for a more rigorous performance-based blast resistant design or assessment, since the current principles as set out in the design guides cannot be fully adequate (Boh et al. 2007).

Although a realistic finite element analysis would be advantageous and is recommended, using the developed FEA programming package would resolve partially the problem of developing an appropriate approach for the design of the stainless steel blast walls, if deterministic analyses were implemented in the assessments. The nature of the input design parameters for assessing the blast walls, in particular the explosion loading scenarios, are stochastic (i.e. random); therefore, a relaibility approach needs to be developed. In addition, for implementing the reliability results for design and assessments, a performancebased design approach is required. For such design, performance levels of the blast wall structures need to be developed (e.g., Serviceability, Damage and Collapse levels), based on various explosion events.

By defining the uncertainties in different properties as random variables, it is possible to efficiently implement simulation strategies in assessing the structural performance. The response parameters can be obtained by linking the simulated values with the finite element models. These values can be used to perform reliability analysis directly or by considering an implicit performance function (e.g., using response surface methods). This paper provides a framework for developing the performance-based design guidelines for blast wall structures. These structures are unique in terms of the possible uncertainties, especially for dynamic response considerations. Also, there is no current guidance on reliability linked design considerations for these structures. It is expected that this paper will address this research gap for these structures. 
In this direction, the authors (Hedayati et al., 2013) developed finite element probabilistic studies at various levels, considering the dynamic effects and nonlinearities in geometric and material properties. It was noticed that the correlation sensitivity results are dissimilar at different time steps in the blast simulation. Hence further linear dynamic analysis were conducted without any non-linearity effects (Hedayati, M. H. et al. 2014), which confirmed that the maximum response is not sensitive to load duration and that the response of the structure is less dynamic. The influence of dynamic effects on the response of these structures was studied in Hedayati et al. (2018), where it was observed that the structural response for a wide range of profiled blast walls was mainly quasi-static or static, as opposed to dynamic. The present paper utilises this understanding to develop a novel performance-based design approach and associated framework using probabilistic reliability results based on enhanced automated FEA models.

Then, further improvement on FEA modelling was carried out to develop a performancebased design approach and associated framework using the probabilistic reliability results. This paper therefore presents the investigations carried out on developing the performancebased design method for typical profiled barrier structures, implementing the probabilistic approach. Initially, by implementing Ansys (ANSYS 2012) and using the enhanced APDL finite element modelling programming package developed earlier (Mohammad $\mathrm{H}$. et al. 2018), the blast wall with consideration of upper and lower connections is developed. The observations from preliminary deterministic analyses, such as the onset of nonlinearity and more importantly the ultimate capacity provide better understanding of the structural responses and to identify failure modes. Various related uncertainties in explosion loadings, material and section properties are considered in the probabilistic assessments by using random input variables and associated probability distributions. In addition, probabilities of occurrences for specified response values and response sensitivity analyses are investigated. 
The design criteria and the maximum allowable response values are also specified to be investigated and discussed.

It should be noted that as part of the above-mentioned research studies, the comparison of reliability methods was carried and justifications for using the approach and methods were presented; accordingly, the same reliability approach has been implemented in the present paper. 


\section{Introduction}

The uncertainties associated with explosion resistance assessment have been well investigated and identified by many researchers. However, the consideration of these uncertainties in most design and assessment guidelines is restricted to the choice of design loads that incorporate factors related to material, loading characteristics and dynamic effects. These factors are mainly based on engineering judgment and often calibrated in a way that the resultant designs are fairly limited to the acceptable practice (Wen 2001).

Recent developments in the reliability of structures, for example for seismic design, confirmed that prescriptive and code-based procedures would not able to fulfil the expectation of varying reliability requirements (Wen 2001). Hence a more rational approach, known as "Performance-based Design", has gradually been developed. The performancebased design is an attempt to assess a system or structure with predictable performance under specific loading conditions. Performance-based design explicitly evaluates how a structure is likely to perform; given the potential hazard it is expected to experience, considering all associated uncertainties (Folic 2015). In fact, it is an effort to assess structural components with anticipated demand and capacity performance (Huang et al. 2012).

The approach of performance-based design is not a new in structural engineering applications. The concept was initially proposed and employed in 1963 for the construction of buildings in Olso and the associated criteria were then developed and utilised by the International Organisation for standardisation (ISO) in some building codes (Mohamed Ali and Louca 2008). Nowadays the concept of performance-based design is widely being employed by various codes and standards, for buildings, and especially for earthquake design. The concept of performance-based design has been introduced to the Oil and Gas industry during the last decade in the context of goal settings (Yasseri 2003). However, the 
method has not gained substantial popularity in this industry, as each project remains unique, with specific challenges in many respects (Yasseri 2003).

The nature of the input design parameters for assessing the blast walls, in particular the explosion loading scenarios, are stochastic (i.e. random); in fact, design engineer should deal with various uncertainties in the explosion loadings and the complex blast wall behaviour, considering dynamic and nonlinearity effects in the evaluation and assessment process. Considering these variable parameters in the design would therefore demand a relaibility approach to be developed. In addition, for implementing the reliability results for design and assessments rationally, a performance-based design approach is required, considering various performance levels of the blast wall structures (e.g., Serviceability, Damage and Collapse levels), in-line with various explosion events.

For blast wall structures, there are two main areas for application of performance-based design: uncertainties associated with explosion hazard assessment and the evaluation of structural performance. These areas are also known as "Demand and Capacity". The demand, which is associated with blast overpressure loading, can be defined in terms of return period, or the probability of exceedance diagrams; whereas, load carrying capacity can be evaluated implementing various analysis methods and relevant software packages.

A multi-level assessment approach should be implemented for performance-based design. Accordingly, various target levels for demand and load carrying capacity are required to be investigated, developed and utilized. The target levels for "Demand" consist of different explosion overpressure loadings and scenarios which are mainly based on CFD and QRA assessments, presented by probability of exceedance and return period of the explosion events. The demand target levels can be varied for each installation and their locations in the 
installation; whereas, the target levels for load carrying capacity are the predefined damage states or levels, presented by stress, strain and deflection.

The approach for assessing demand, used in earthquake design and blast resistance assessment, was discussed and presented by other researches (Ghobarah 2001; Yasseri 2012; Yasseri 2003), and an overview of the approach is given in this study. 


\section{Finite element analysis models}

\subsection{Section properties and connection configuration}

For considering appropriate connection details, sensitivity analyses were initially carried out for each individual model. Figure 1 gives an overview of the connections and associated parameters for the section properties.

Although a number of models were developed and assessed, a base model was selected and presented in this paper for this particular study. It should be noted that these FEA models have been developed appropriately as per associated guidelines, and international standards (Brewerton and FABIG TN5. 1999; Louca and Boh 2004).

In addition, the developed FEA programming can generate a complex blast wall structure, with a number of bays (e.g. 100) and spans, for the analyses and assessments; however, for this particular study, to present the developed approach, the model presented by Figure 1 has been selected and assessed.
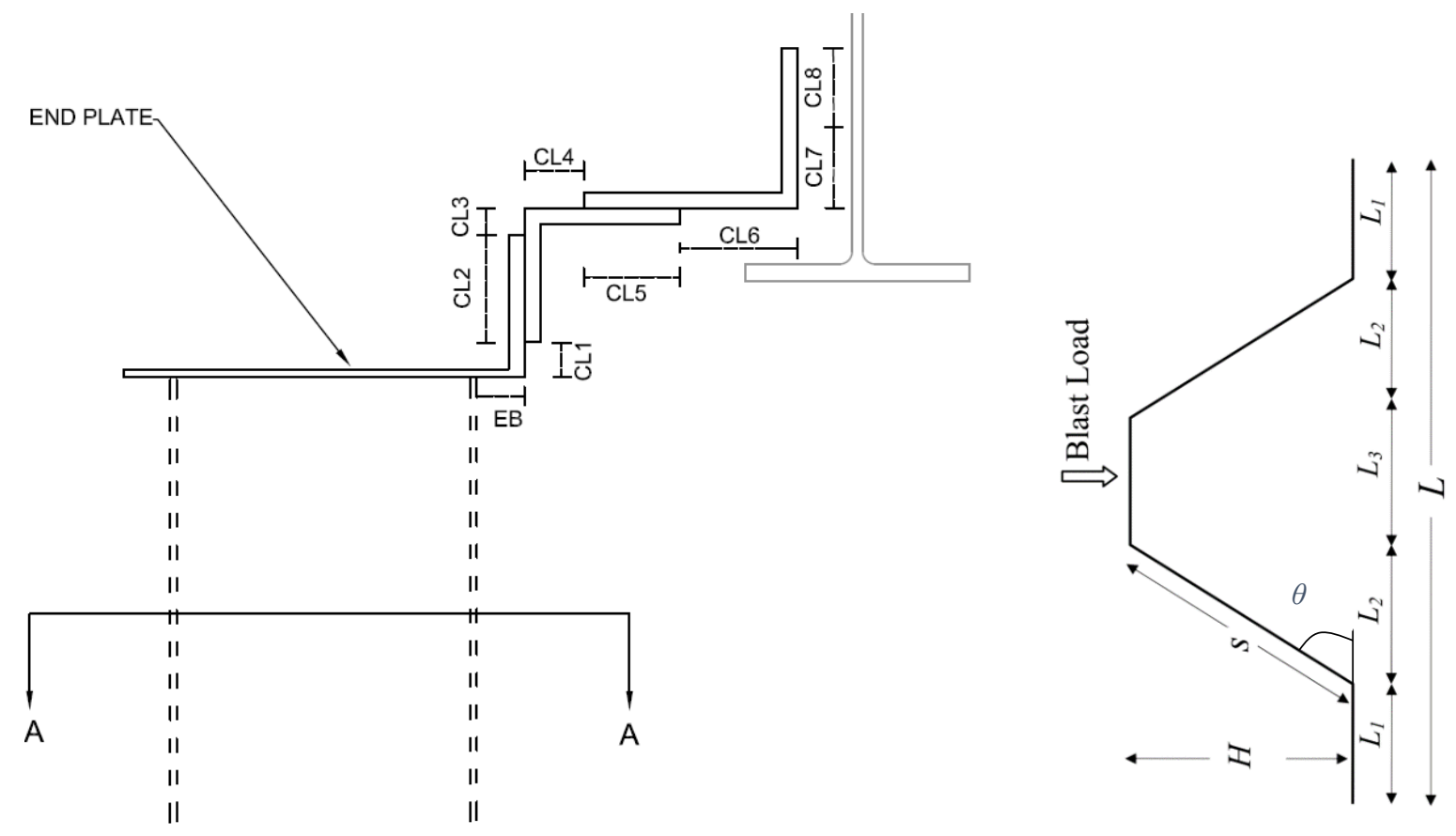

A - A

Figure 1. Upper and lower parametric connection details and section property parameters 
For any large engineering component which has symmetric elements or sub-parts, symmetric boundary conditions can be developed to reduce the total degrees of freedom, and consequently to speed up the analyses process. A symmetry region refers to dimensionally decreasing the model based on a mirror plane. Therefore, in this study, the blast walls have been developed by using 3D shell elements (i.e. SHELL181) with symmetric boundary conditions, and the displacement along the wall and in-plane and out-of-plane rotations of the vertical fabricated edges have been constrained.

Table 1 presents the input parameters for the section properties and Table 2 shows input values for the connection parameters associated with developed analysis model.

Table 1 Mean values of geometric properties for selected model

\begin{tabular}{cccccccc}
\hline $\boldsymbol{T w}$ & $\boldsymbol{L 1}$ & $\mathbf{L 2}$ & $\mathbf{L 3}$ & $\boldsymbol{H}$ & Span & $\boldsymbol{\theta}$ & Reference \\
$(\boldsymbol{m m})$ & $(\boldsymbol{m m})$ & $(\boldsymbol{m m})$ & $(\mathbf{m m})$ & $(\boldsymbol{m m})$ & $(\boldsymbol{m m})$ & $($ Deg. $)$ & \\
\hline 11 & 200 & 320 & 240 & 554 & 6000 & 60 & (Louca and Boh 2004)
\end{tabular}

Table 2 Connection Parameters (Lengths and Thicknesses)

\begin{tabular}{cccccccc}
\hline $\boldsymbol{C L 1}$ & $\boldsymbol{C L 2}$ & $\boldsymbol{C L 3}$ & $\boldsymbol{C L 4}$ & $\boldsymbol{C L 5}$ & $\boldsymbol{C L 6}$ & $\boldsymbol{C L 7}$ & $\boldsymbol{C L 8}$ \\
\hline $50 \mathrm{~mm}$ & $200 \mathrm{~mm}$ & $50 \mathrm{~mm}$ & $110 \mathrm{~mm}$ & $180 \mathrm{~mm}$ & $210 \mathrm{~mm}$ & $150 \mathrm{~mm}$ & $150 \mathrm{~mm}$ \\
\hline $\boldsymbol{C T 1}$ & $\boldsymbol{C T 2}$ & $\boldsymbol{C T 3}$ & $\boldsymbol{C T 4}$ & $\boldsymbol{C T 5}$ & $\boldsymbol{C T 6}$ & $\boldsymbol{C T 7}$ & $\boldsymbol{C T 8}$ \\
\hline $30 \mathrm{~mm}$ & $60 \mathrm{~mm}$ & $30 \mathrm{~mm}$ & $30 \mathrm{~mm}$ & $60 \mathrm{~mm}$ & $30 \mathrm{~mm}$ & $30 \mathrm{~mm}$ & $30 \mathrm{~mm}$ \\
\hline
\end{tabular}

\subsection{Material properties}

Strain rate effects are implemented in the assessments. Among the available strain rate methods in the literature, one of the relevant models to consider strain rate effects in stainless steel is the Cowper-Symonds model [ Hernandez, C, et al 2013]. In this study, this model is incorporated for strain rate enhancement of yield stress in the computation of dynamic yield stress as: 


$$
\sigma=\left[1+\left(\frac{\dot{\varepsilon}^{p l}}{\gamma}\right)^{m}\right] \cdot \sigma_{0}
$$

Where,

$\sigma_{0}$ is yield stress at zero plastic strain (i.e. nominal static stress) and $\sigma$ is the dynamic stress,

$\&^{l}$ is the plastic strain rate measured in sec-1, $\gamma$ and $\mathrm{m}$ are the strain rate coefficients.

Table 3 gives the material and strain rate parameters and associated input mean values. Figure 2 presents the nonlinear (i.e. bilinear) material curve associated with Table 3, and considered in the assessments. In addition, in all the analyses the effects of geometric nonlinearity are also included.

Table 3 Material Properties for the FEA model

\begin{tabular}{cccccc}
\hline \multicolumn{2}{c}{ Material } & & & \multicolumn{2}{c}{ Material-Strain rate } \\
\hline FY (Minimum & Fu (Ultimate & $\mathrm{E}$ & $\varepsilon$ & $\mathrm{m}=$ strain rate & $\gamma=$ material \\
Yield Stress) & Tensile Strength) & $\begin{array}{c}\text { (Young's } \\
\text { modulus, })\end{array}$ & (Elongation) & hardening parameter & viscosity parameter \\
$460 \mathrm{MPa}$ & $740 \mathrm{MPa}$ & $200 \mathrm{GPa}$ & $25 \%$ & 0.25 & 400 \\
\hline
\end{tabular}

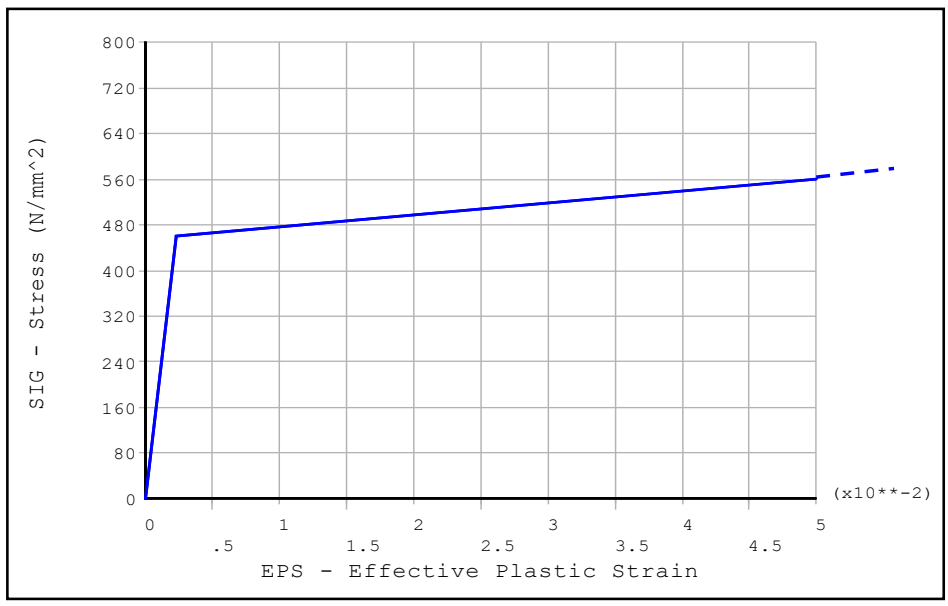

Figure 2. Bilinear Stress-Strain Curve-Non-linear Analyses 


\subsection{Explosion loading}

Figure 3 presents the blast loading versus time, considered in the analyses.

Table 4 presents the mean values of the loading input parameters.

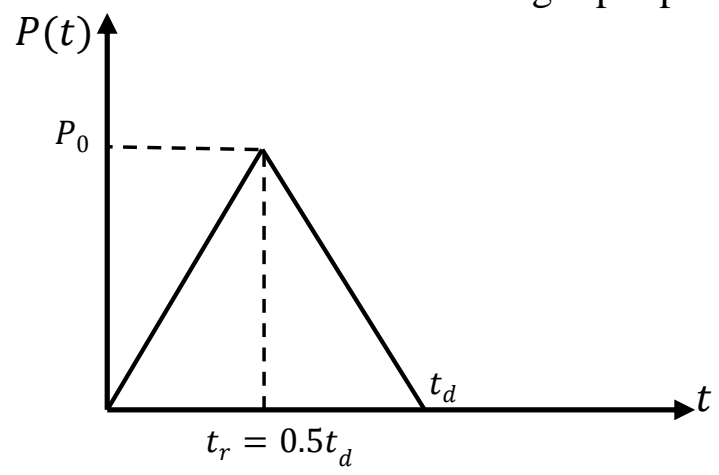

Figure 3. Triangular Blast Pressure Load Pulse $-\left(t_{r}=0.5 t_{d}\right)-$ distributed uniformly in a spatial sense over the entire blast wall

Table 4 Mean values of maximum peak overpressure and duration

Loading parameter

\begin{tabular}{cc}
\hline Peak Overpressure & $3.5(0.35)$ \\
Loading-bar $(\mathbf{M p a})$ & \\
\hline Time duration $\left(\boldsymbol{t}_{d,}, \boldsymbol{s}\right)$ & 0.15
\end{tabular}

\subsection{Deterministic analyses and screening the results}

As part of the developed approach for performance-based assessment, it is quite important to perform deterministic analyses, using mean input values, to ensure that appropriate input parameters are selected. For example, if there is an overall or global collapse failure when using the mean input values, it implies that there is no strong justification for performing probabilistic assessments. In other words, a major failure of the structure under the circumstances and environmental condition defined by the mean input values shows inadequacy of the capacity leading to inappropriate design. Accordingly, various deterministic nonlinear dynamic analyses were carried to investigate the structural behaviour and to choose appropriate input parameters. In fact, deterministic analyses are 
required to determine local and global capacities of the structure and to outline some of the differences before proceeding to the probabilistic assessments.

Figure 4 gives an overview of the finite element modelling and Figure 5 shows the transient dynamic nonlinear response, considering the mean input values. As can be seen, the maximum displacement response is about $200 \mathrm{~mm}$ and this can be compared with maximum allowable output parameters (e.g., ranging from Span/100 to Span/8) as discussed in this study later.

The present study fully implements the dynamic effects and nonlinearities in geometric and material properties.

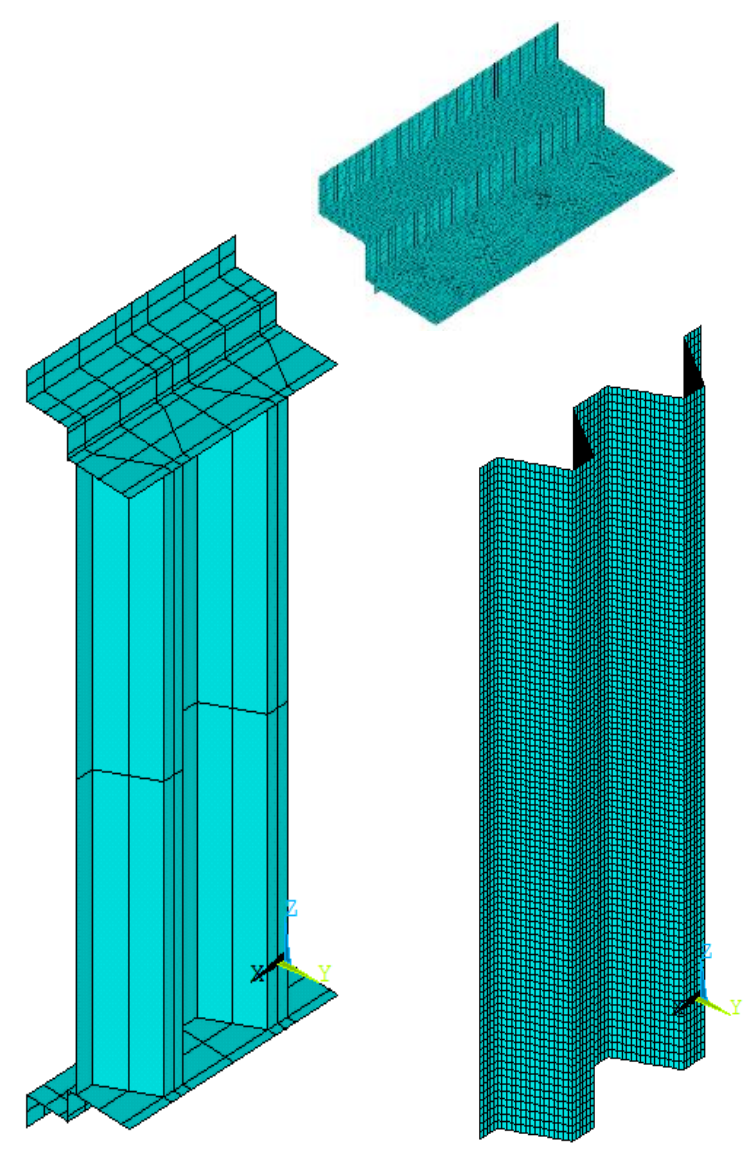

Figure 4 Finite element representation of the study model 


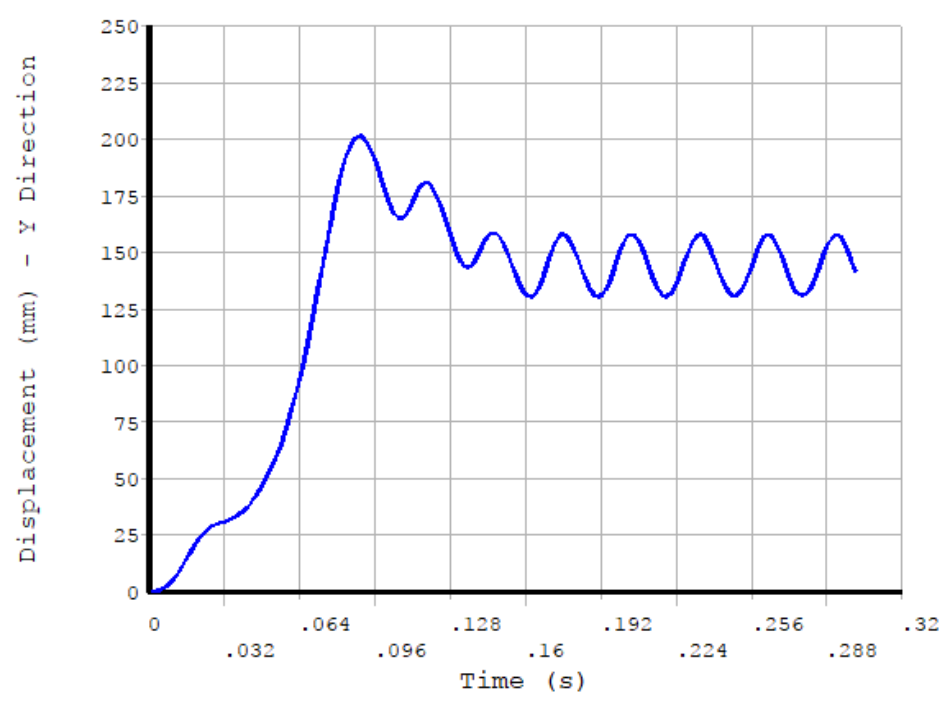

\section{Figure 5 Transient dynamic response, Displacement, study model}

Another important area to be investigated in deterministic assessments is the onset of nonlinearity which is the boundary between elastic and plastic responses. In fact, the response at this point, gives the maximum elastic response which can be evaluated against permissible elastic criteria, as discussed in this study later. Figure 6 presents the maximum elastic displacement response. Identifying the maximum plastic response is crucial to identify the capacity of blast walls accurately. These maximum nonlinear responses can be defined in terms of displacements and strains. Figure 7-9 present the maximum inelastic displacement, strain at the connections (i.e. lower and upper connections), and strain at the span or wall. Comparing the maximum plastic strains (i.e. EPTO, total equivalent von-Mises strain) for the connections and wall, it can be seen that the first and main failure is associated with the connections, with a maximum total (i.e. elastic +plastic) strain value of 0.159 . In other words, the governing design criteria would be associated with the connections, rather than the span itself. 

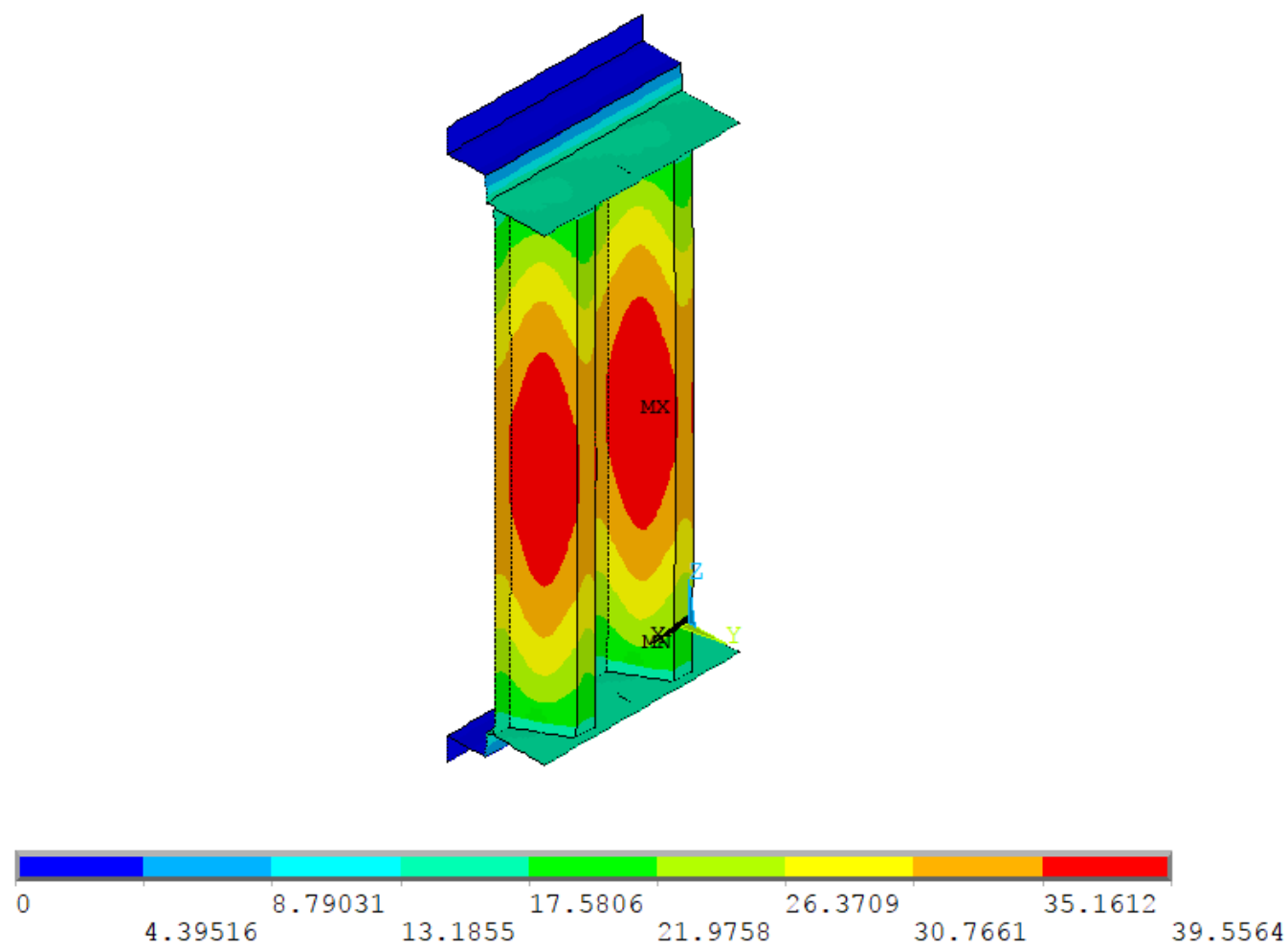

Figure 6 Maximum elastic displacement (mm)
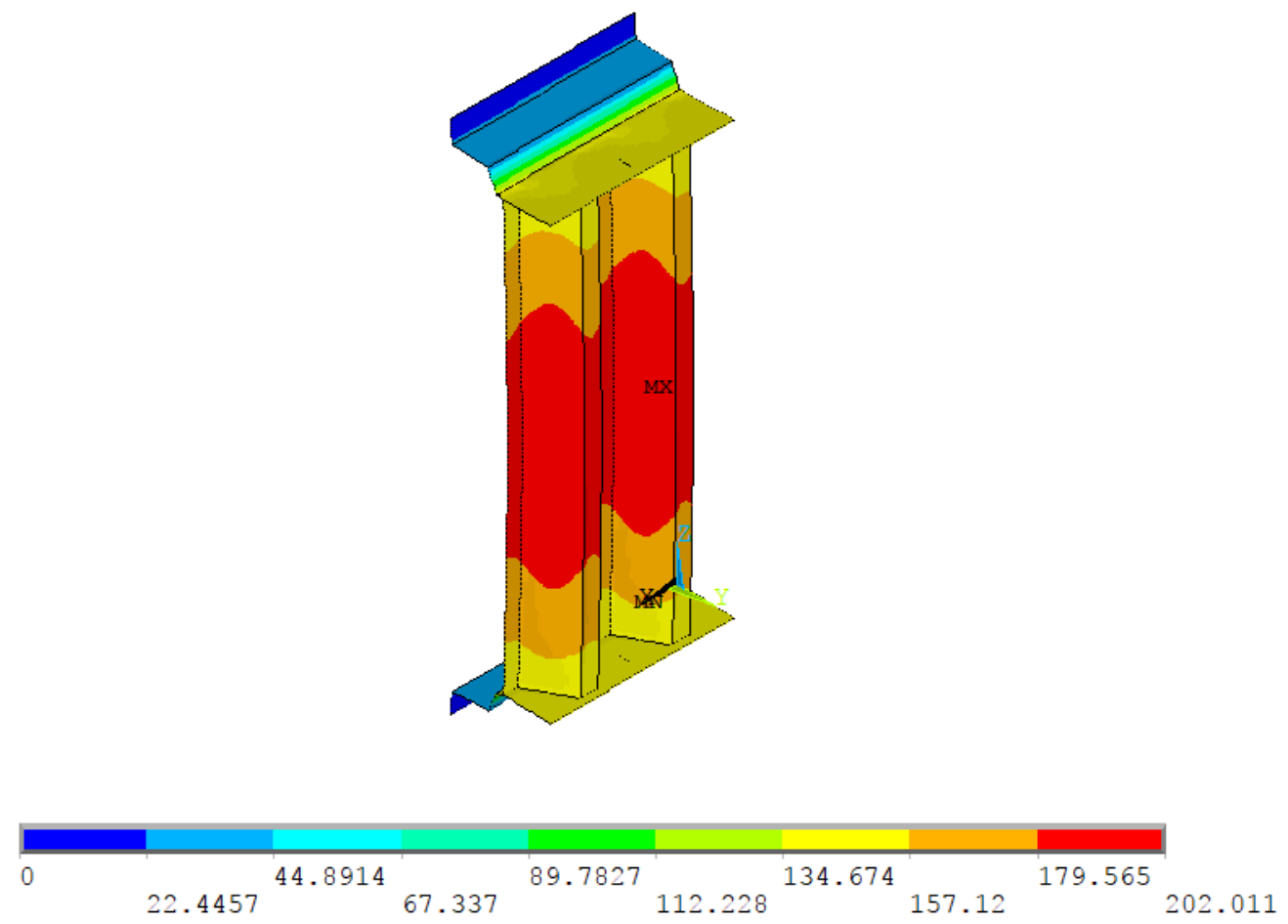

Figure 7 Maximum response, displacement (mm) 

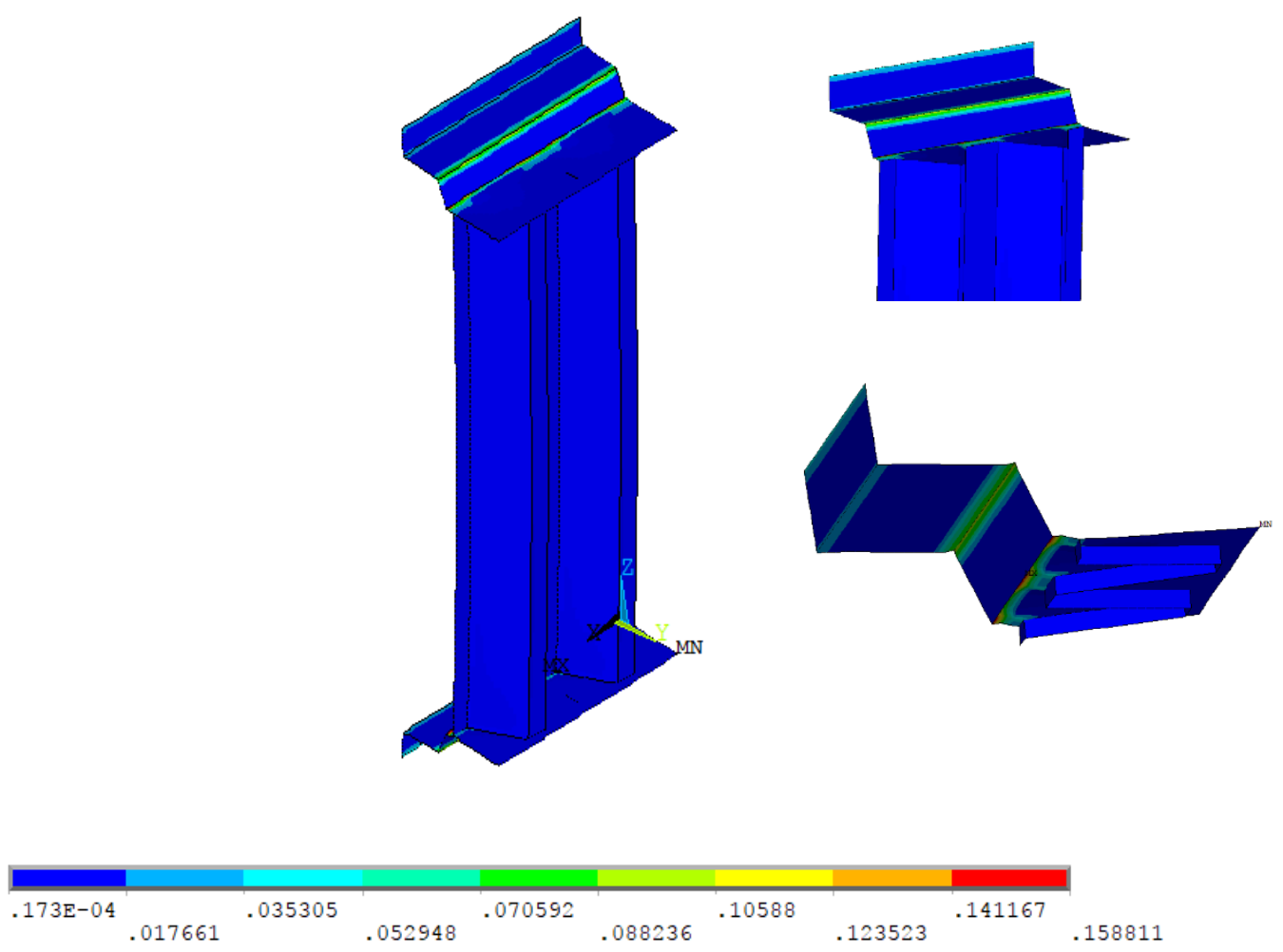

Figure 8 Maximum response, Total equivalent von Mises strain (EPTO)
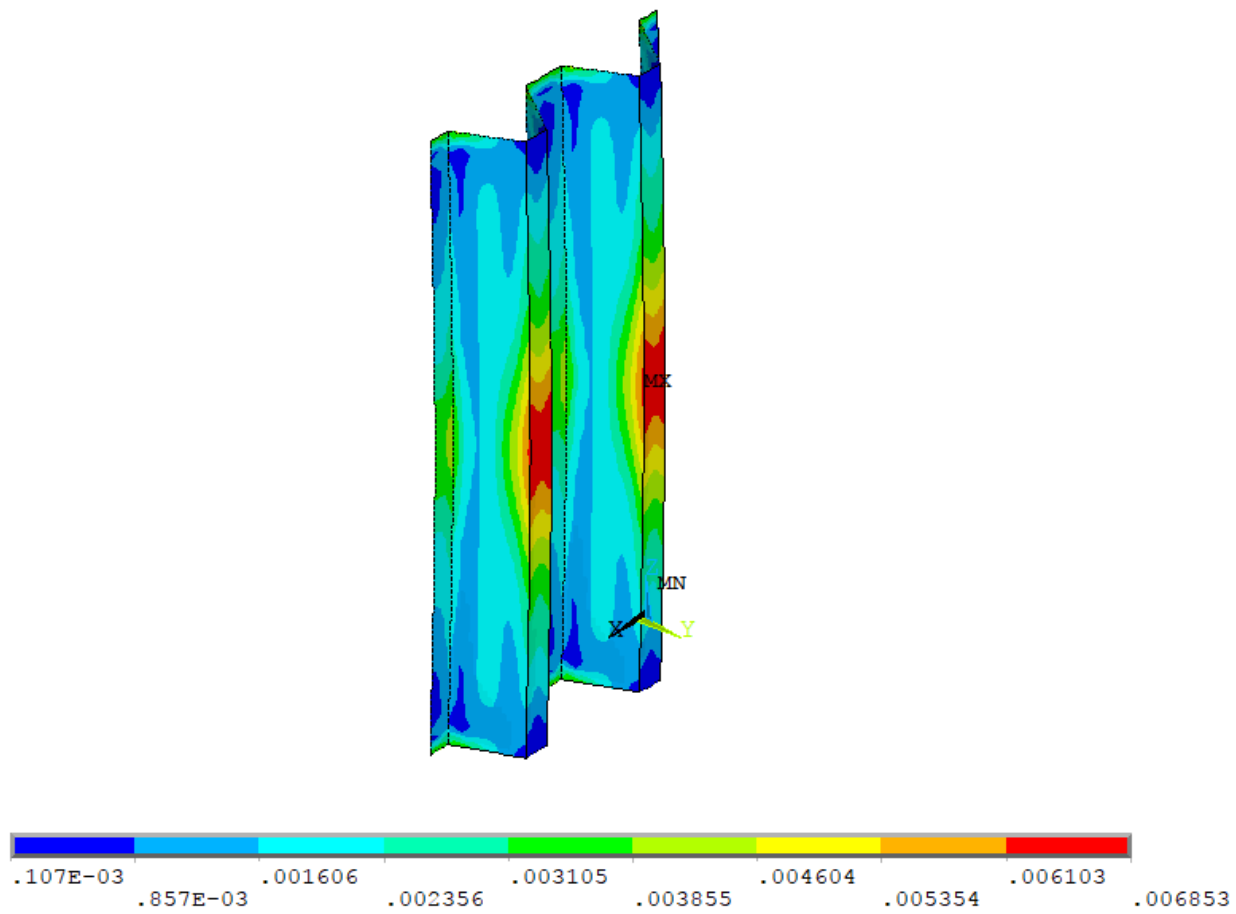

Figure 9 Maximum response, Total equivalent von Mises strain (EPTO), for Span, 


\section{Structural reliability assessment}

For performing reliability assessment, the same approach which was introduced and gradually developed in previous studies by the authors (Hedayati, MH et al. 2018) is implemented. Again, uncertainties are defined as random variables and MCS and the LHS approach are utilized. Based on the previous probabilistic assessments carried out for this research study, 300 simulation loops were considered initially for the analysis and verified for accuracy. The maximum elastic and nonlinear random responses related to deflection and equivalent strain of the blast wall components (i.e., connections and wall) are considered as the limiting properties. Response sensitivity analyses are carried out to investigate the influence of each random input parameter. The reliability results are discussed leading to the performance-based assessment stage.

\subsection{Probabilistic assessment parameters}

The deterministic base-line model has ten parameters that are now regarded as random input variables and characterized by their expected mean values and standard deviation.

Table 5 and 6 present the variables along with the considered distribution models and parameters. These random input variables are assumed to be statistically independent.

One dominant aspect in the probabilistic assessment of profiled barrier blast walls is to identify uncertainties, stemming from various sources, and then implement them accurately in the associated analyses. In this study, to have a wide range of random modal analysis models, geometric properties are introduced as the uncertainties and are considered in the probabilistic analyses by modelling the properties as random variables represented by probability distributions. Probabilistic analysis results can be sensitive to the tail of the probability distribution and therefore, an appropriate approach/method to select the proper 
distribution type is necessary (Det Norske Veritas 1992). In this study, for all of the random variables, except for the profiled barrier thickness, Tw, which uses the normal or Gaussian distribution is assumed, for demonstrative purposes.

Table 5 Parametric Variables for Probabilistic Analysis: Geometry, Loading and Material

\begin{tabular}{|c|c|c|c|c|c|c|c|c|}
\hline \multirow[b]{2}{*}{$\begin{array}{l}\text { Random } \\
\text { variable }\end{array}$} & \multicolumn{2}{|c|}{ Geometry } & \multicolumn{2}{|c|}{ Impulse Loading } & \multicolumn{4}{|c|}{ Material } \\
\hline & $\begin{array}{l}\text { Height, } \\
H(\mathrm{~mm})\end{array}$ & $\begin{array}{l}\text { Thickness, } \\
T w(\mathrm{~mm})\end{array}$ & $\begin{array}{l}\text { Time } \\
\text { duration, } \\
t_{d}(\mathrm{~s})\end{array}$ & $\begin{array}{l}\text { Peak } \\
\text { pressure } \\
\text { load } \\
P_{0} \text { (bar) }\end{array}$ & $\begin{array}{l}\text { Minimum } \\
\text { Yield } \\
\text { Stress } \\
F_{y}(\mathrm{MPa})\end{array}$ & $\begin{array}{l}\text { Ultimate } \\
\text { Tensile } \\
\text { Strength, } \\
F_{u}(\mathrm{MPa})\end{array}$ & $\begin{array}{l}\text { Young's } \\
\text { modulus, } \\
E(\mathrm{GPa})\end{array}$ & $\begin{array}{l}\text { Elongation } \\
(\%)\end{array}$ \\
\hline Mean & & 11 & 0.15 & 3.5 & 460 & 740 & 200 & 25 \\
\hline $\begin{array}{l}\text { Coefficient } \\
\text { of variation }\end{array}$ & 0.05 & $\begin{array}{l}\sim 0.1 \\
(+/-1 \mathrm{~mm})\end{array}$ & 0.1 & 0.15 & 0.1 & 0.1 & 0.05 & 0.05 \\
\hline $\begin{array}{l}\text { Probability } \\
\text { distribution }\end{array}$ & Gaussian & Uniform & Gaussian & Gaussian & Gaussian & Gaussian & Gaussian & Gaussian \\
\hline
\end{tabular}

Table 6 Parametric Variables for Probabilistic Analysis, Strain Rate

\begin{tabular}{lcc}
\hline \multicolumn{3}{c}{ Strain rate } \\
\hline $\begin{array}{l}\text { Random } \\
\text { variable }\end{array}$ & $\begin{array}{c}\text { hardening } \\
\text { parameter }\end{array}$ & $\begin{array}{c}\text { viscosity } \\
\text { parameter }\end{array}$ \\
\hline Mean & 9 & 400 \\
Coefficient of variation & 0.1 & 0.2 \\
Probability distribution & Gaussian & Gaussian \\
\hline
\end{tabular}

The Coefficients of variation have been based on expert engineering judgment. The selection of Probability distribution is based on the related DNV code (Det Norske Veritas 1992). It should be noted that a base model was selected and developed for this study to provide a practical example, to present the developed approach. The geometric condition is 
mainly used from the reference (Louca and Boh 2004) and the loading condition is dependent on various factors.

\subsection{Probabilistic results}

\subsubsection{Connection results}

For blast wall profiled barriers, the connections and the wall are the two main structural components required for assessment and design. The upper and lower connections play an important role in the assessments, as they transfer the explosion loadings to the structural frames (e.g., topside module frame), and in many cases, there are loadings from the topside frames to the blast walls via these connections.

The cumulative distribution functions (CDFs) of the variables are very useful for the design engineer, to check that the probability of the maximum responses remains below a specified limiting value or defined criteria. For assessing the connections, strain responses, ranging from maximum elastic (EPEL) to maximum plastic (EPTO) responses are the important output parameters to be investigated and considered when using a plastic design (or Load and Resistance Design) approach. Figure 10 shows the CDFs associated with maximum elastic equivalent von Mises strain (EPEL) and maximum total equivalent von Mises strain (EPTO) for the connections of this study model. As can be seen from Figure 10, the probability of having a maximum total strain (EPTO) up to (i.e. equal or smaller than) 0.2 is $88.2 \%$. In other words, the probability of having a maximum total strain (EPTO) greater than 0.2 is $11.8 \%$.

It should be noted that the strain values (i.e. EPTO, EPEL, and EPPL) are based on the $3 \mathrm{D}$ equivalent von Mises principle and therefore, the relation between stress and strain (e.g., the onset of nonlinearity) is not purely based on the stress-strain curve which relates to 1D theory and only experimental tensile tests. 

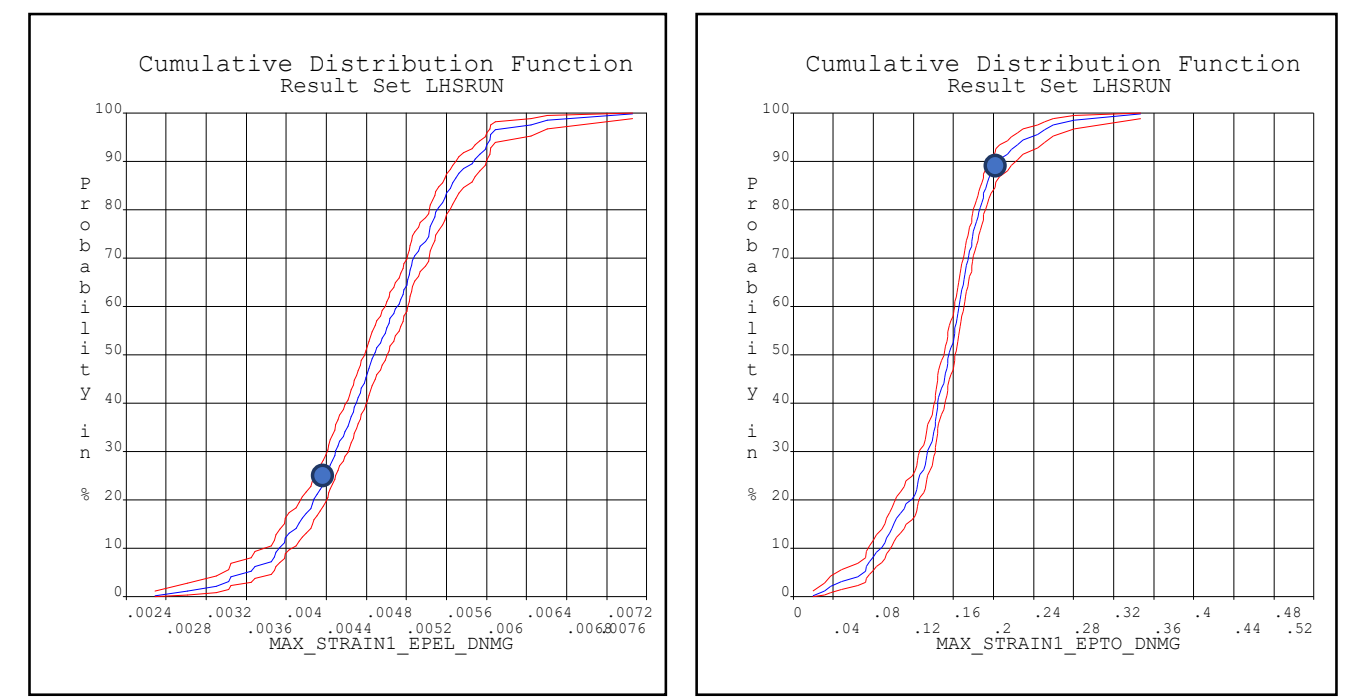

Figure 10 CDF of Maximum Strain-Connections-Elastic (left), Total (right)

\subsubsection{Wall span results}

For the walls, the two key response types which need to be reviewed for the assessments are displacements and strains. The total elastic and inelastic displacements and strains are regarded as the main response parameters. To review and check the responses for the simulations, sample values can be developed. Figure 11 presents response sample values for the total and elastic displacements.
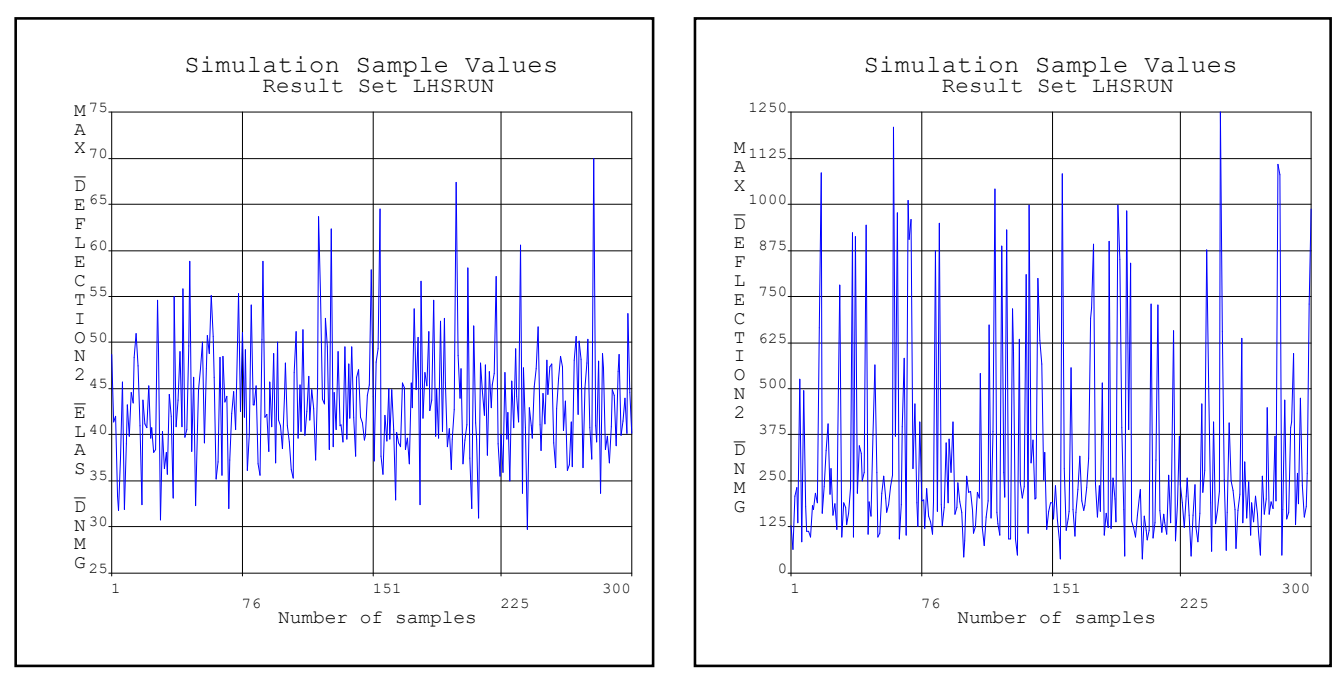

\section{Figure 11 Response Sample Value, Deflection, Elastic (left), Total (right)}

Figure 12 and Figure 13 present the cumulative distribution functions associated with elastic and nonlinear responses (i.e. maximum displacements and strains), for the walls. 
Providing a reasonable ductility level (the ratio of total response to maximum elastic response) is a vital consideration for a structure with plastic design basis such as blast walls. To check the ductility, for instance, from Figure 12, the maximum elastic deflection associated with $30 \%$ and $90 \%$ probabilities are about $40 \mathrm{~mm}$ and $51 \mathrm{~mm}$ respectively; whereas, from this figure, it can be seen that maximum total deflection related to $30 \%$ and $90 \%$ probabilities are about $170 \mathrm{~mm}$ and $750 \mathrm{~mm}$ respectively. From the above-mentioned detail, it can be observed that the ratios of total inelastic (i.e nonlinear) responses to total elastic response are greater than 4.0 (i.e. $170 / 40$ and 750/51), confirming the existence of a good level of ductility within this structure. Figure 13 also presents the strain responses for the wall span.
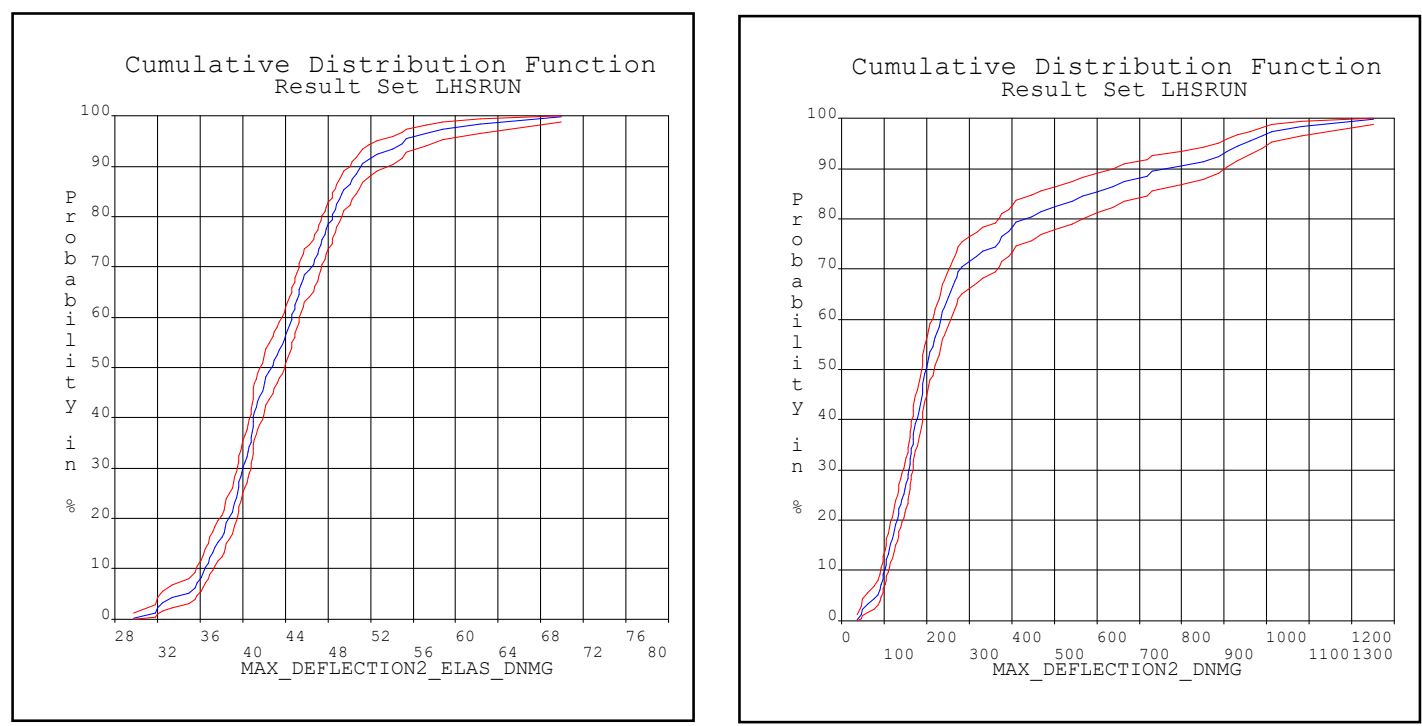

Figure 12 CDF of Maximum Deflection-Elastic (left), Total (right)
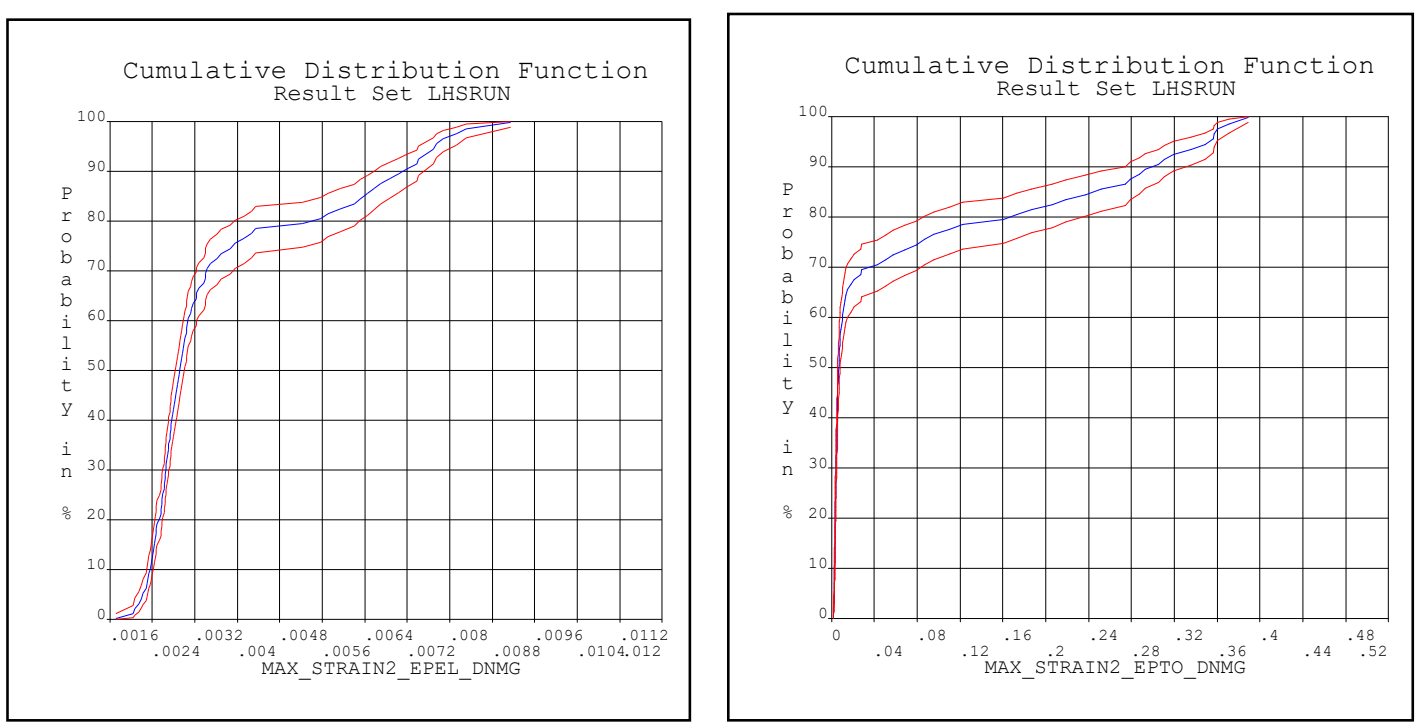


\section{Figure 13 CDF of Maximum Strain, Mid-Span, Elastic (left), Total (right)}

As discussed earlier, these CDFs are very useful for design engineers to identify specific responses associated with particular probabilities of exceedance, and is crucial for Performance-based design. In performance-based design, each level is required to have a specific probability of exceedance (e.g., $0.5 \%$ for collapse prevention level).

\subsubsection{Investigation of CDF's for the connections and wall}

A summary of the probabilities of responses exceeding defined values based on the CDFs presented earlier is given in Table 7. As can be seen from Table 7, which summarizes the CDF results, the probability of having a maximum displacement greater than $750 \mathrm{~mm}$ is about $10.1 \%$, confirming a $89.9 \%$ chance of having a maximum displacement less than or equal to $750 \mathrm{~mm}$. The table also confirms that there is only $2 \%$ probability of having a maximum elastic displacement response greater than $60 \mathrm{~mm}$. Table 7 also shows that the chances of having the maximum total equivalent von Mises strain (EPTO) greater than 0.2 are $17.7 \%$ and $11.8 \%$ for mid-span and connections respectively. It would clearly help design engineers or researchers to highlight critical responses based on their probability of occurrences or failures. For example, for this particular case, having about $18 \%$ probability of having EPTO greater than 0.2, probably means failure and therefore the input design parameters should be modified for new design; but if this is an existing blast wall structure, other remedial options such as strengthening can be implemented. Table 7 also shows lower and upper bounds of probabilities, considering a 95\% confident limit. The estimation of lower and upper limits are calculated based on the mean, standard deviation and sample size

Table 7 Probability of Maximum Responses Exceeding Specified Values

\begin{tabular}{lllll}
\hline Response & Criteria & Probability & $\begin{array}{l}\text { Lower } \\
\text { Bound }\end{array}$ & $\begin{array}{l}\text { Upper } \\
\text { Bound }\end{array}$ \\
\hline Maximum & $250 \mathrm{~mm}$ & 0.358 & 0.305 & 0.413 \\
Displacement $>$ & $500 \mathrm{~mm}$ & 0.177 & 0.137 & 0.223 \\
& $750 \mathrm{~mm}$ & 0.101 & 0.070 & 0.138 \\
\hline
\end{tabular}




\begin{tabular}{|c|c|c|c|c|}
\hline & $1000 \mathrm{~mm}$ & 0.028 & 0.014 & 0.051 \\
\hline \multirow{4}{*}{$\begin{array}{l}\text { Maximum Elastic } \\
\text { Displacement > }\end{array}$} & $30 \mathrm{~mm}$ & 0.997 & 0.986 & 1.000 \\
\hline & $40 \mathrm{~mm}$ & 0.699 & 0.646 & 0.749 \\
\hline & $50 \mathrm{~mm}$ & 0.139 & 0.103 & 0.181 \\
\hline & $60 \mathrm{~mm}$ & 0.020 & 0.008 & 0.040 \\
\hline \multirow{4}{*}{$\begin{array}{l}\text { Mid-Span, Maximum } \\
\text { Elastic Equivalent } \\
\text { Strain (EPEL) > }\end{array}$} & 0.002 & 0.993 & 0.979 & 0.999 \\
\hline & 0.004 & 0.241 & 0.195 & 0.292 \\
\hline & 0.006 & 0.174 & 0.134 & 0.220 \\
\hline & 0.008 & 0.033 & 0.017 & 0.057 \\
\hline \multirow{4}{*}{$\begin{array}{l}\text { Mid-Span, Maximum } \\
\text { Total Equivalent Strain } \\
\text { (EPTO) }>\end{array}$} & 0.05 & 0.287 & 0.238 & 0.340 \\
\hline & 0.1 & 0.232 & 0.187 & 0.282 \\
\hline & 0.15 & 0.207 & 0.164 & 0.255 \\
\hline & 0.2 & 0.177 & 0.137 & 0.223 \\
\hline \multirow{4}{*}{$\begin{array}{l}\text { Connections, Maximum } \\
\text { Elastic Equivalent } \\
\text { Strain (EPEL) }>\end{array}$} & 0.002 & 1.000 & 1.000 & 1.000 \\
\hline & 0.004 & 0.876 & 0.836 & 0.910 \\
\hline & 0.006 & 0.067 & 0.042 & 0.099 \\
\hline & 0.008 & 0.000 & 0.000 & 0.000 \\
\hline \multirow{4}{*}{$\begin{array}{l}\text { Connections, Maximum } \\
\text { Total Equivalent Strain } \\
\text { (EPTO) }>\end{array}$} & 0.05 & 0.961 & 0.935 & 0.979 \\
\hline & 0.1 & 0.853 & 0.810 & 0.890 \\
\hline & 0.15 & 0.559 & 0.503 & 0.614 \\
\hline & 0.2 & 0.118 & 0.085 & 0.157 \\
\hline
\end{tabular}

\section{Performance-based design parameters}

Performance-based assessment for blast walls requires two main elements of investigation: one is associated with the demand (i.e. overpressure explosion loading for this study) and the other with capacity which is related to resistance of the structure, i.e., material, section properties and boundary conditions. As mentioned earlier, there are several key 
activities associated with performance-based design, including setting up of goals, estimating demand, evaluating capacity, and defining target levels and criteria.

\subsection{Performance objectives}

The initial step for performance-based assessment is to set up goals and objectives and develop the corresponding performance level(s). The performance objective for explosion resistance design should be developed, focusing on the levels, demand (i.e. explosion loading) and capacity (i.e. resistance). Each performance level is presented by linking a specified maximum allowable damage to an identified explosion hazard, i.e., overpressure or demand level. A performance objective may have several levels of demand and capacity i.e., multi-level performance objective.

As discussed earlier, the performance objective may vary according to installation type (e.g., manned, unmanned or remote, production, living quarter, and integrated platforms) and location. Therefore, cooperation of professionals from multiple disciplines is necessary to set up realistic goals and objectives, considering a series of scenarios. For this study, at the initial stage, a four-level performance objective has been proposed and presented in Table 8 .

Table 8 Initially proposed performance objectives 


\begin{tabular}{lll}
\hline Level & Intensity & Performance Levels/Limit States \\
\hline $\boldsymbol{L 1}$ & Light & Serviceability \\
$\mathbf{L 2}$ & Moderate & Damage Control \\
$\mathbf{L 3}$ & Severe & Ultimate \\
$\boldsymbol{L 4}$ & Very Severe & Collapse \\
\hline
\end{tabular}

Earlier reliability studies and the associated response sensitivity analyses have confirmed that the most influential design input parameter for blast walls is the explosion loading. Therefore, the selection of the design overpressure explosion loading has a strong influence on the performance objectives of the resultant designs. The actual reliability performance against a specific limit state, however, varies depending on the limit state and the associated uncertainties.

Many international codes and standards consider two levels (e.g., SLB and DLB) for platforms (i.e., jackets and topsides). Adding more levels of explosion design for specific levels of performance can enforce the performance goals. However, the selection of the additional design explosion and corresponding performance goals needs to be carefully carried out to ensure internal consistency. As mentioned, considering the proposed approach for developing performance levels, three levels out of the initially developed four levels, are selected.

\subsection{Demand assessment and uncertainty}

Based on the QRA and CFD analyses, for each specified performance level, demand or maximum overpressure loading can be estimated with regard to their probability of occurrence. However, the main issue is the associated uncertainties in specifying an appropriate or maximum permissible overpressure loading. In addition, any changes or modifications in equipment layout or locations result in altering the critical explosion scenarios. To tackle this problem, for this research study, the related demand uncertainties are 
incorporated in the probabilistic assessments by introducing the overpressure explosion loadings as random variables.

The approach of demand evaluation was discussed in this study, and accordingly, based on the selected or defined performance objectives, and considering the probability of exceedance and platform life time, the mean return period of the event is estimated. Table 9 presents the initial and preliminary development of four levels for the demand assessment and calculated interval occurrence. In the later stage, three out of four levels, based on engineering justification, are reasonably selected for the assessments presented in this study. It should be noted that the selection of the number of performance levels is required to be investigated case by case, engaging professional design engineers, verification bodies as well as clients or owners.

Table 9 Internal occurrence versus probability of exceedance for the developed levels

\begin{tabular}{llll}
\hline Level & $\begin{array}{l}\text { Performance } \\
\text { Levels }\end{array}$ & $\begin{array}{l}\text { Return period of the event (years), } \\
\text { with 50 years design life }\end{array}$ & $\begin{array}{l}\text { Probability of } \\
\text { Exceedance }\end{array}$ \\
\hline L1-Light & Serviceability & 10 & $99.5 \%$ in 50 Years \\
L2-Moderate & Damage Control & 100 & $39.5 \%$ in 50 Years \\
L3-Severe & Ultimate & 1000 & $5 \%$ in 50 Years \\
L4-Very Severe & Collapse & 10000 & $0.5 \%$ in 50 Years
\end{tabular}

The platform design life is considered to be 50 years

Identifying an accurate peak overpressure for each level presented in

Table $\mathbf{4}$ is very complicated, as a result of various related uncertainties, and care should be taken while estimating these values, as they have substantial effects on performance-based design. Nevertheless, for this research study, a new approach has been proposed by 
considering the peak overpressure associated with collapse performance level and introducing it as a random variable. A mean value and a standard deviation represent the explosion loading, and the probabilities of exceedance or occurrence are investigated and targeted for capacity or resistance rather than the loading.

\subsection{Capacity uncertainty}

Capacity has direct relation with the strength, mass, and stiffness of the blast wall structure. Capacity uncertainty is attributed to material inconsistency, fabrication tolerances or errors, installation misalignments, and structural modelling errors such as the highly unpredictable brittle failure of the connections. The uncertainties in material properties, section property tolerances and misalighnments are represented in terms of probability distributions and the associated parameters. To tackle the problem with the FEA modelling errors, all blast wall analysis models developed and used for this paper were verified by implementing the approach presented in the previous study (Hedayati, Mohammad H. et al. 2018).

\subsection{Target levels and damage states}

For enforcing the reliability performance objectives and goals, the target probabilities are required to be set directly for the limit states rather than for the design explosion. In the assessment, if the limit state probabilities are below the target values, the performance of the structure is satisfactory.

In developing reliability-based design methods, one of the main steps is to start from these target reliability goals corresponding to physical limit states such as the onset of nonlinearity and initial collapse and accordingly to develop the required deterministic design arrangements, which will produce a design that satisfies these goals. This approach was developed and used for this study. 
Structural elements are categorized either as deformation-controlled or forcecontrolled. However, for blast wall assessments, the damage control and near collapse performance levels are not at the load level the structure can tolerate. This is because the responses go beyond elastic domain (e.g., plastic region); in fact, they are on a displacement (or strain) level which the blast wall can withstand without major failure (i.e. collapsing). This is because of nonlinearity and ductility of the materials which allow the yielding of some elements resulting in a plastic behaviour.

For this study, three performance levels (i.e. out of four), including serviceability, damage control, and collapse prevention are selected. For each level, three limit states associated with displacement, strain at connections and strain at span or wall, are considered. Figure 14 presents the target performance functions, defined based on the selected target levels. As can be seen from these figures, each level has a unique probability of exceedance and a specified damage level or criteria (i.e. limiting response value). For example, Figure 14 shows that $99.5 \%, 39.5 \%$ and $0.5 \%$ are the probability of exceedance for serviceability, damage and collapse levels respectively, considering a design life of 50 years. For example, Figure 14 also presents the response criteria for each level (for example, for serviceability level, the criteria are L/100). As shown in the figure, the best fitted curve, using the three defined criteria presents the target performance function and any response above this target curve would be associated with unacceptable performance (e.g., the curve presented by the red colour). In addition, the responses below the target level (e.g., the curve shown by the green colour), highlight acceptable performance region. One of the main advantages of developing such a curve is to focus on the optimum design, which is in fact, matched with the defined target performance. 
Table 10 shows target levels and damage statements considered for the performancebased assessment presented in this research study.

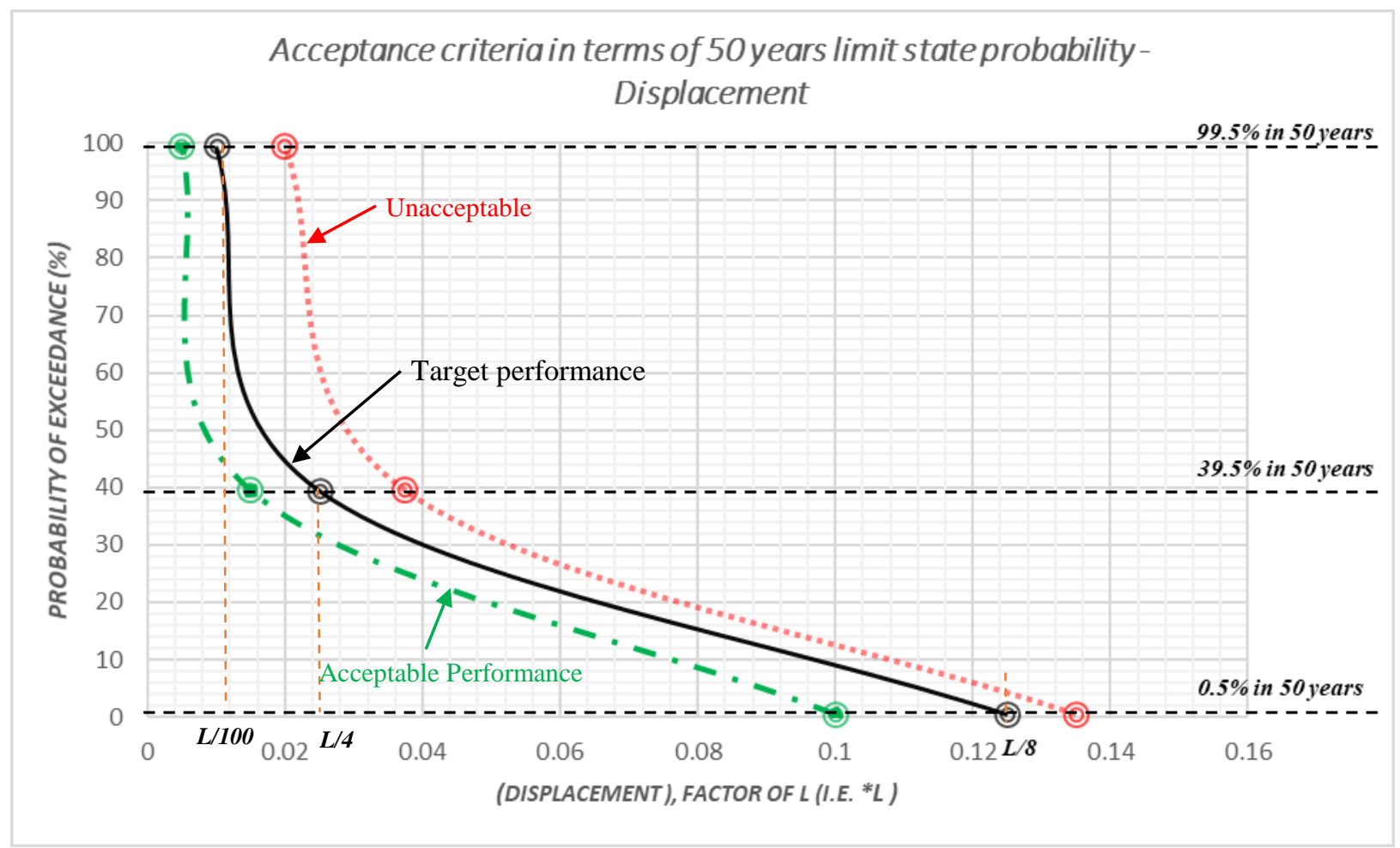

Figure 14 Tri-level acceptance criteria(displacement) in terms of 50-year limit state probability

Table 10 Target levels and damage states

\begin{tabular}{|c|c|c|c|c|c|}
\hline Level & $\begin{array}{l}\text { Return period of the } \\
\text { event (years), within } 50 \\
\text { years design life }\end{array}$ & $\begin{array}{l}\text { Chance }(\%) \\
\text { in } 50 \text { Years }\end{array}$ & $\begin{array}{l}\text { Displacement } \\
\text { limitation }\end{array}$ & $\begin{array}{l}\text { Strain, at } \\
\text { connections }\end{array}$ & $\begin{array}{l}\text { Strain, at wall } \\
\text { (Allowable) }\end{array}$ \\
\hline$L 1(S L)$ & 10 & $\begin{array}{l}99.5 \% \text { in } 50 \\
\text { Years }\end{array}$ & $\mathrm{L} / 100$ & 0.004 & 0.003 \\
\hline$L 2(D L)$ & 100 & $\begin{array}{l}39.5 \% \text { in } 50 \\
\text { Years }\end{array}$ & $\mathrm{L} / 40$ & 0.075 & 0.05 \\
\hline $\mathrm{L3}(\mathrm{CL})$ & 10000 & $\begin{array}{l}0.5 \% \text { in } 50 \\
\text { Years }\end{array}$ & $\mathrm{L} / 8$ & 0.20 & 0.15 \\
\hline
\end{tabular}


Failure strain for deterministic assessments is based on the minimum yield stress (Fy). However, for probabilistic or performance-based assessments, the strength/strain levels have been proposed based on service levels (i.e. serviceability, damage, ultimate strength). Selecting these levels would probably require engaging various parties, including the client, operator, and verification parties such as Lloyds and DNV. In many cases, the information can be provided by suppliers and manufacturers. It should be noted that in this paper, an approach for performance-based assessments of blast wall structures is developed. In practice, the selected parameters may require to be discussed with the above-mentioned parties before starting the assessments.

\subsection{Result summary and discussions}

An overview of a typical schematic of the considered performance levels and the associated regions for limit states is shown in Figure 15. Based on the calculation procedure discussed and considered in this study, $0.5 \%, 39.5 \%$, and $99.5 \%$ are the chances of occurrence of the blast event, with return periods of 10, 100, and 10,000 years respectively, considering a 50 year design life. It should be noted that for existing assets, the design life can be estimated according to the remaining life of the platform or the blast wall, based on an engineering judgement.

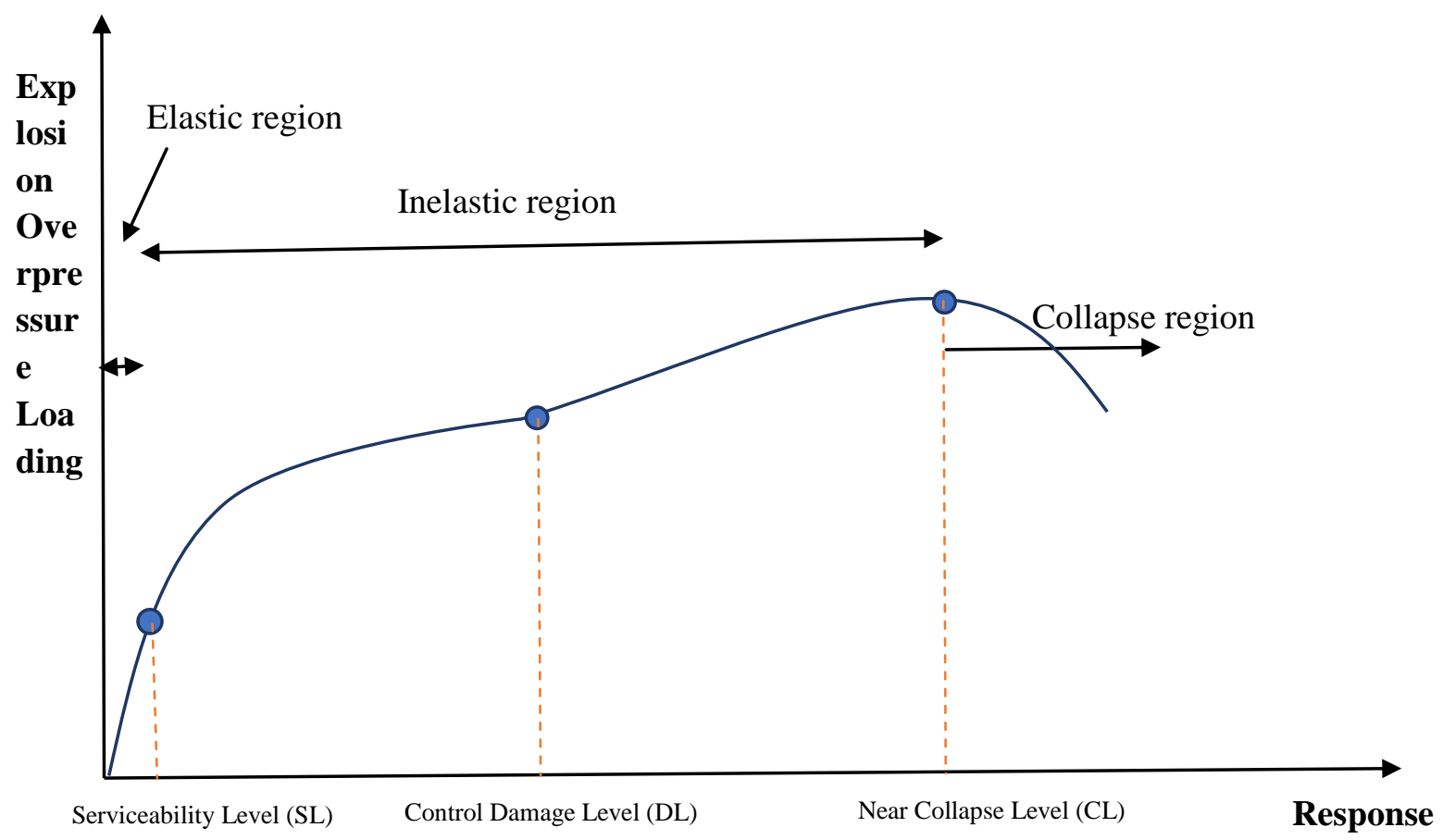




\section{Figure 15 Typical schematic performance curve for blast walls}

For each performance level, there are three limit states (i.e., displacement, strain at the connections, strain at span), and therefore, in total, nine criteria are considered as acceptable target values as presented by Table 11. As mentioned earlier, the strain values are based on the $3 \mathrm{D}$ equivalent von Mises theory. This means that the relation between stress and strain (e.g., the onset of nonlinearity) is not based purely on the stress-strain curve. For example, for this model the maximum elastic strain at the connections based on the stress-strain curve, and associated with deterministic analysis is 0.0023 , whereas the maximum elastic equivalent von Mises strain is 0.0049 , as presented by Table 11 .

Table 11 presents the results of the performance-based assessment. As can be seen, five out of ten of the achieved reliability values are greater than specified target values, meaning that the limit states with the defined criteria cannot be satisfied fully, and therefore, the design of this blast wall with the defined parameters, along with the proposed reliability performance-based assessment, would not be acceptable. Table 11 also shows the "Remaining and Requiring" capacities, based on the target criteria and achieved random response values. For example, for the maximum elastic response, the remaining or reserve capacity is calculated as follows:

Reserve Capacity $(\%)=\frac{(\text { Target value }- \text { Achieved Value }) * 100}{\text { Target value }}=\frac{(72-31)}{72}=57$

These capacities can be used for design optimization, and also to help design engineers to find out critical failures and areas of concern to be investigated and consequently to amend the design if applicable. 
Table 11 Performance-based assessment results

\begin{tabular}{|c|c|c|c|c|c|c|}
\hline Objective & $\begin{array}{l}\text { Performance } \\
\text { level }\end{array}$ & Target & Target value & $\begin{array}{l}\text { Achieved } \\
\text { Value }\end{array}$ & $\begin{array}{l}\text { Remaining } \\
\text { capacity }(\%)\end{array}$ & $\begin{array}{c}\text { Requiring } \\
\text { capacity (\%) }\end{array}$ \\
\hline \multirow{3}{*}{$\begin{array}{l}\text { Max } \\
\text { Displacement }\end{array}$} & $\begin{array}{l}\text { SL }(99.5 \% \text { or } \\
\text { less in } 50 \text { years) }\end{array}$ & Span/100 & 72 & 31 & 57 & \\
\hline & $\begin{array}{l}\text { DL ( } 39.5 \% \text { or } \\
\text { less in } 50 \text { years) }\end{array}$ & Span/40 & 180 & 234 & & 30 \\
\hline & $\begin{array}{l}\text { CL }(0.5 \% \text { or } \\
\text { less in } 50 \text { years })\end{array}$ & Span/8 & 900 & 1186 & & 32 \\
\hline \multirow{3}{*}{$\begin{array}{l}\text { Strain at Mid- } \\
\text { Span }\end{array}$} & $\begin{array}{l}\text { SL }(99.5 \% \text { or } \\
\text { less in } 50 \text { years) }\end{array}$ & 0.003 & 0.003 & 0.0019 & 15 & \\
\hline & $\begin{array}{l}\text { DL ( } 39.5 \% \text { or } \\
\text { less in } 50 \text { years) }\end{array}$ & 0.05 & 0.05 & 0.0106 & 79 & \\
\hline & $\begin{array}{l}\text { CL }(0.5 \% \text { or } \\
\text { less in } 50 \text { years })\end{array}$ & 0.15 & 0.15 & 0.3822 & & 155 \\
\hline \multirow{3}{*}{$\begin{array}{l}\text { Strain at Lower } \\
\text { or Upper } \\
\text { Connections }\end{array}$} & $\begin{array}{l}\text { SL }(99.5 \% \text { or } \\
\text { less in } 50 \text { years })\end{array}$ & 0.004 & 0.004 & 0.0028 & & 13 \\
\hline & $\begin{array}{l}\text { DL ( } 39.5 \% \text { or } \\
\text { less in } 50 \text { years) }\end{array}$ & 0.075 & 0.075 & 0.1661 & & 121 \\
\hline & $\begin{array}{l}\text { CL }(0.5 \% \text { or } \\
\text { less in } 50 \text { years })\end{array}$ & 0.2 & 0.2 & 0.3220 & & 61 \\
\hline
\end{tabular}




\section{Summary and conclusion}

A new approach is proposed for performance-based assessment of profiled barrier blast walls and the related framework is discussed. An example is given in detail on the assessment and design, implementing the developed procedure, and using a step by step approach. The approach has one preliminary and three main stages as follows:

1. Preliminary review of performance objectives

2. Deterministic assessment

3. Reliability analyses and assessments

4. Performance-based design assessment

Initially, a preliminary study on performance objectives is carried out, and consequently four-performance objectives are proposed, and accordingly three performance levels (two primary and one secondary) are selected. Deterministic analyses are then carried out to investigate and to find out the critical failure modes and initial permissible capacities. In case of any major failure at this stage, the design input parameters need to be amended. The probabilistic analyses are performed, and the associated results are investigated, and the important responses are tabulated and discussed.

The performance-based assessment is carried out, using the considered performance levels. For each level, the hazard (explosion) demands and maximum allowable structural capacities are introduced in terms of their probabilities of exceedances and the associated limit states are presented. The details of probabilities of exceedances, limit states, and criteria (i.e., target values or allowable responses) for each level are investigated and discussed. The 
results based on the probabilities of exceedance for connections and wall are tabulated and non-conformities are identified to be reviewed and discussed by a qualified competent engineer. If there is no failure (i.e., all achieved values are smaller than the specified limiting values), the assessment is satisfactory, and the design is acceptable. Whereas, if there are any major failures, the input parameters need to be altered and the system needs to be reanalyzed, to make the design acceptable.

In addition, from the results of this particular study on the blast wall, it can be concluded that structural design is highly dependent on the consequence of the structural limit states and associated defined criteria (i.e., maximum allowable response). Therefore, setting up an appropriate criterion for each component and each level is a vital consideration in the design and assessment process. It is also confirmed that implementing a minimum estimated design life is a reasonable consideration to setting up reliability and performance objectives and goals.

\section{References:}

ANSYS. (2012). "ANSYS Inc., Documentation. Release 14.0." ANSYS Inc., Documentation. Release 14.0., .

Biggs, J. M. (1964). "Introduction to Structural Dynamics

." McGraw-Hill, .

Boh, J. W., Louca, L. A., and Choo, Y. S. (2007). "

Finite Element Analysis of Blast Resistant Structures in the Oil and Gas Industry ." ABAQUS Users' Conference, .

Brewerton, R., and FABIG TN5. (1999). "Design Guide for Stainless Steel Blast Wall: Technical Note 5, Fire and Blast Information Group (FABIG)." Fire and Blast Information Group (FABIG), .

Det Norske Veritas. (1992). "Structural Reliability Analysis of Marine Structures: Classification Note No. 30.6." . 
Folic, R. (2015). "

Performance Based Seismic Design of Concrete Buildings Structures - Bases."

"DOI:10.14415/konferencijaGFS 2015.026", .

Ghobarah, A. (2001). "Performance-based design in earthquake engineering: state of development." Engineering Structures, 23(8), 878-884.

Haifu, Q., and Xueguang, L. (2009). "

Approach to Blast Wall Structure Computing in Ocean Engineering

." Proceedings of the International Conference on Industrial and Information Systems, IIS '09,

Hedayati, M. H., Sriramula, S., and Neilson, R. D. (2014). "Linear Dynamic Reliability Analysis of Profiled Blast Walls." ASCE-ICVRAM-ISUMA Conference, Liverpool, UK, .

Hedayati, M., Sriramula, S., and Neilson, R. D. (2013). "

Non-Linear Dynamic Reliability Analysis of Profiled Blast Walls ." 11th International Conference on Structural Safety and Reliability (ICOSSAR), New York, USA, .

Hedayati, M. H., Sriramula, S., and Neilson, R. D. (2018). "Dynamic behaviour of unstiffened stainless steel profiled barrier blast walls." Ships and Offshore Structures, 13(4), 403-411.

Hernandez, C., Maranon, A., Ashcroft, I.A. and Casas-Rodriguez, J.P., (2013). A computational determination of the Cowper-Symonds parameters from a single Taylor test, 37 (7), pp.4698-4708.

Huang, M. F., Chan, C. M., and Lou, W. J. (2012). "Optimal performance-based design of wind sensitive tall buildings considering uncertainties." Computers \& Structures, 9899(Supplement C), 7-16.

Liang, Y. H., Louca, L. A., and Hobbs, R. E. (2007). "Corrugated panels under dynamic loads." Int.J.Impact Eng., 34(7), 11851201.

Louca, L. A., and Boh, J. W. (2004). "

Analysis and Design of Profiled Blast Walls. Research Report 146." Hse, .

Mohamed Ali, R. M., and Louca, L. A. (2008). "Performance based design of blast resistant offshore topsides, Part I: Philosophy." Journal of Constructional Steel Research, 64(9), 10301045.

Wen, Y. K. (2001). "Reliability and performance-based design." Structural Safety, 23(4), 407-428.

Yasseri, S. (2012). "Goal Setting Approach for Blast Resistant Design." FABIG, Research \& Development, Newsletter Published by Steel Construction Institute, UK, .

Yasseri, S. (2003). "Performance Based Blast Resistant Designs." FABIG, Research \& Development, Newsletter, R476, (35),. 
